\title{
Retrospective data analyses of social and environmental determinants of malaria control for elimination prospects in Eritrea
}

\author{
Selam Mihreteab ${ }^{{ }^{*}+}$, Jailos Lubinda ${ }^{2 \dagger}$, Bingxin Zhao ${ }^{3}$, Alfonso J. Rodriguez-Morales ${ }^{4,5,6}$, \\ Ajlina Karamehic-Muratovic ${ }^{7}$, Aman Goitom ${ }^{1}$, Muhammad Yousaf Shad ${ }^{8 \dagger}$ and Ubydul Haque $9,10,11 \dagger$
}

\begin{abstract}
Background: The present study focuses on both long- and short-term malaria transmission in Eritrea and investigates the risk factors. Annual aggregates of information on malaria cases, deaths, diagnostics and control interventions from 2001 to 2008 and monthly reported data from 2009 to 2017 were obtained from the National Malaria Control Programme. We used a generalized linear regression model to examine the associations among total malaria cases, death, insecticide-treated net coverage, indoor residual spraying and climatic parameters.

Results: Reduction in malaria mortality is demonstrated by the milestone margins of over $97 \%$ by the end of 2017 . Malaria incidence likewise declined during the period (from 33 to 5 per 1000 population), representing a reduction of about $86 \%\left(R^{2}=0.3\right)$ slightly less than the decline in mortality. The distribution of insecticide treated nets generally declined between 2001 and $2014\left(R^{2}=0.16\right)$ before increasing from 2015 to 2017, while the number of people protected by indoor residual spraying slightly increased $\left(R^{2}=0.27\right)$. Higher rainfall was significantly associated with an increased number of malaria cases. The covariates rainfall and temperature are a better pair than IRS and LLIN to predict incidences. On the other hand, IRS and LLIN is a more significant pair to predict mortality cases.

Conclusions: While Eritrea has made significant progress towards malaria elimination, this progress should be maintained and further improved. Distribution, coverage and utilization of malaria control and elimination tools should be optimized and sustained to safeguard the gains made. Additionally, consistent annual performance evaluation of malaria indicators would ensure a continuous learning process from gains/threats of epidemics and resurgence in regions already earmarked for elimination.
\end{abstract}

Keywords: Malaria, Vector-borne diseases, Public health, Control, Elimination, Eritrea

\section{Background}

Following a nationwide malaria epidemic in 1998, Eritrea has made remarkable progress on basic health indices [1], most notably in reducing malaria incidence $(80 \%)$ and mortality (90\%) by 2015 compared with the 1998 baseline

\footnotetext{
*Correspondence: smuqubay@gmail.com

†Selam Mihreteab and Jailos Lubinda contributed equally to this work

†'Muhammad Yousaf Shad and Ubydul Haque_-Joint senior authors

${ }^{1}$ National Malaria Control Programme, Ministry of Health, Asmara, Eritrea

Full list of author information is available at the end of the article
}

[2]. This progress placed Eritrea in the spotlight as one of Africa's model countries in malaria control. In 2016, the country was one of the eight recipients of the African Leaders Malaria Alliance Award (ALMA) for excellence in achieving the Millennium Development Goals (MDGs) target for malaria [3].

Through the Ministry of Health, Eritrea established a Health Management Information System (HMIS) [4] and joined other African countries in calling for a malariafree continent by 2030. The World Health Organization (WHO) Global Technical Strategy for Malaria 2016-2030 
was launched towards this effort [5]. Eritrea's target for malaria incidence and mortality reduction is $40 \%$ and $75 \%$ by 2020 and 2025 , respectively, with the long-term goal to ultimately eliminate and prevent re-establishment of malaria by 2030 [6].

Incidence of malaria tends to peak in October in most zobas, while the months March-April mark the main transmission season in the coastal areas. The most common malaria parasite is Plasmodium falciparum which accounts for roughly $67 \%$ of all malaria cases [7]. Plasmodium vivax accounts for nearly $30 \%$ and few proportions of mixed infections [7]. Anopheles arabiensis is the main vector of malaria in the country followed by $A n$. d'thali, An. cinereus, An. rhodesiensis, An. squamosus and An. rupicolus [8].

Established in 1995, the National Malaria Control Programme (NMCP) of Eritrea drafted a strategy of control program by 1997 (Additional file 1: Table S1). In 2000, the NMCP also launched the second national malaria control programme. In 2001, the NMCP conducted the national malaria prevalence survey and planned for malaria interventions (Additional file 1: Table S1). In 2007, the NMCP introduced RDT at the community level and on 2016 HRP2 based RDTs replaced with Pf-pLDH/PanpLDH RDTs. A combination of artesunate + amodiaquine was introduced as a first-line treatment for uncomplicated malaria in 2007 and Artesunate injection was introduced in 2016 for treatment of severe malaria cases. Over the years, the NMCP drafted and revised many policy guidelines to control malaria in Eritrea (Additional file 1: Table S1).

This study is an early assessment of Eritrea's National Malaria Control Programme. It reflects Eritrea's efforts in achieving the needed incremental progress towards 2020, 2025 and 2030 goals. We reviewed the progress made from 2001 to 2017, analyzed risk factors using 2009-2017 monthly reported data, discussed the major strategic efforts and implications of interventions implemented and investigated the role of climatic parameters in the spread of malaria cases in Eritrea. This study also extracted patterns of yearly progress to capture shortterm oscillations that eventually tie in with the prospecting planned milestones towards elimination.

\section{Methods}

\section{Study area}

Eritrea is located to the south-west of the Red Sea, bordered by Ethiopia to the south, Sudan to the north and west, and the Republic of Djibouti to the south-west (Fig. 1) [9]. Nearly 5 million people live in 124,000 square kilometers $[10,11]$. The country is administratively divided into six geographical regions called zobas (Fig. 1) [1, 11, 12]. Malaria is highly seasonal and is prone to epidemics in the western lowlands. Transmission is perennial along rivers, valleys, dams and irrigation projects. The coastal plains have similar malaria situations to the western lowlands, but with notably less precipitation. The highlands are generally free from malaria but are highly prone to malaria epidemics because of the low immunity of these populations. Approximately $70 \%$ of the estimated population (nearly 3.5 million) resides in malaria-endemic areas.

\section{Data sources}

The Ministry of National Development provided all population and projections data from 2001 to 2017 at a growth rate of $2.8 \%$. We obtained malaria epidemiology data from the HMIS, Eritrea. Diagnosis (Additional file 2: Text S1), long-lasting insecticidal net (LLINs) and indoor residual spraying (IRS) data were obtained from the National Malaria Control Programme (NMCP). Health workers at their respective facilities fill different types of registers on a routine daily basis and complete a monthly HMIS summary form. Monthly HMIS summary forms are then sent to a sub-zoba, to which the facility belongs. The HMIS office at sub-zoba retains a copy and sends all monthly HMIS summary forms (i.e. for all facilities administered under it) to the HMIS office at zoba. Referral hospitals electronically send monthly data. Thus, the National HMIS collates monthly data from zobas and referral hospitals electronically. The ministry routinely collects malaria data from out-patient and in-patient facilities including health stations, health centers, district hospitals and referral hospitals throughout the country, with over $90 \%$ completeness and timeliness in reporting [13]. We downloaded the shapefiles from DIVA-GIS (freely available, http://www.diva-gis.org) and analyzed the spatial and temporal data comprised of sub-zoba level aggregations of malaria incidence, mortality, diagnostics and intervention coverage for LLINs from 2001 to 2017. We also used detailed sub-national (district/sub-zoba) incidence and mortality outpatient and inpatient data, as well as sub-zoba level of IRS and LLIN coverage in the period 2009-2017.

\section{Environmental data}

Maximum and minimum daily temperature data (surface air temperature at $2 \mathrm{~m}$ height) were obtained for each location (sub-zoba) from the Climate Forecast System Reanalysis (CFSR) dataset of the National Centers for Environmental Prediction (NCEP) [14]. The CFSR is a global high-resolution $(\sim 33 \mathrm{~km})$ hourly product available from 1979 to 2011, extended to the present as CFSR version 2 at a resolution of $\sim 22 \mathrm{~km}$ [14].

Daily rainfall data were obtained for each location (subzoba) from the Climate Hazards Group Infrared Rainfall 


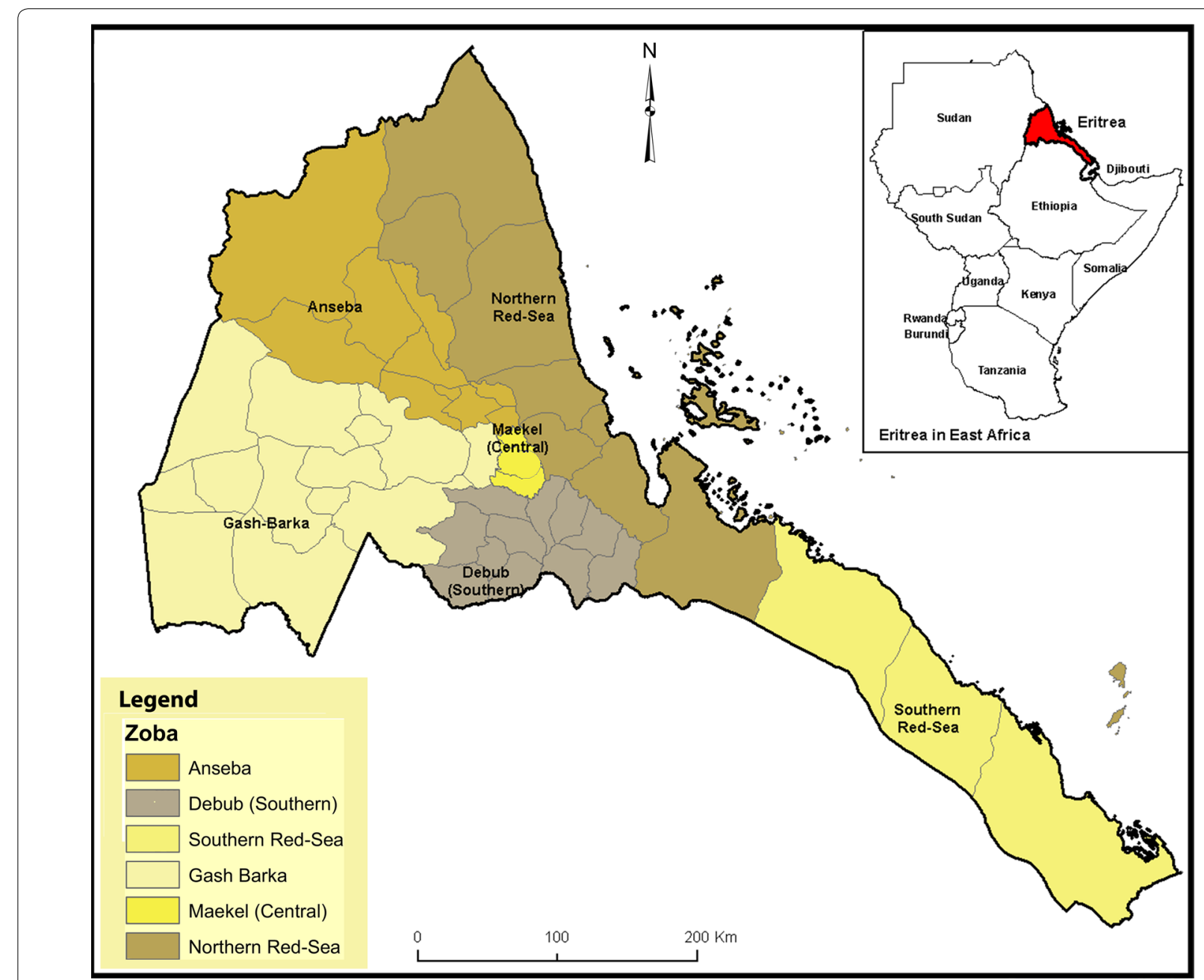

Fig. 1 Location of Eritrea in Africa

with Stations (CHIRPS) dataset developed by the United States Geological Survey (USGS) in collaboration with the Department of Geography, University of California, Santa Barbara [15]. The CHIRPS dataset is a high-resolution $(\sim 5 \mathrm{~km})$ quasi-global $\left(50^{\circ} \mathrm{S}\right.$ to $\left.50^{\circ} \mathrm{N}\right)$ rainfall climatology constructed from a combination of satellite imagery and in-situ data.

\section{Malaria morbidity, mortality, test positivity rate and diagnostics}

We used population estimates as denominators to calculate malaria incidence, mortality, admission and test positivity rates. Malaria incidence and mortality rates were calculated per 1000 population. Test positivity rate (TPR) is the proportion of laboratory-confirmed malaria tests per 100 suspected cases examined. The diagnostic tools used to confirm malaria cases during the reported period included microscopy and rapid diagnosis tests (RDTs). In lower-level health facilities (namely health stations), clinical diagnosis was practiced by health providers lacking diagnostic tools over a decade ago [13], i.e. before 2007. At present, suspected malaria cases are rarely treated on clinical suspicion but only after confirmation with a parasitological diagnosis. In certain circumstances, suspected malaria patients may be treated with anti-malarial drugs in the absence of parasitological diagnosis or a negative result but when the clinician has a strong suspicion that the fever is due to malaria. Even if such a practice is exercised to save the life of the patient, parasitological testing must be repeated every $6-12 \mathrm{~h}$ to confirm and report the case as malaria or not.

LLINs coverage was computed using data aggregated from all distribution channels including mass campaigns, antenatal clinics, and other partners. A rate of two household residents per net calculated as 
\% people covered by LLINs

$$
=\frac{\text { No. of LLINs distributed in the past } 3 \text { years } \times 2}{\text { Population at risk }}
$$

was used to calculate coverage as per Kilian et al. [16], Haque et al. [17] and Kamuliwo et al. [18]. Calculation of administrative coverage of LLINs was guided by the WHO Pesticide Evaluation Scheme testing process, which averages the net lifespan (decay of efficacy) at 3 years if the nets retain full efficacy given their minimum standard of insecticidal activity for this period. Decline in bed net coverage due to wear and tear, and loss is estimated at $8 \%$ during year $1,20 \%$ in year 2 and $50 \%$ in year 3 . One net is also distributed to 1.8 persons to compensate for odd household sizes (e.g. 2 nets, instead of 1.5 nets, are given to a household of 3 persons). The true decay and net loss may vary from place to place [19] and depend on access levels [16]. The percentage ratio of national level coverage and people protected by indoor residual spraying (IRS) was calculated as:

$\frac{\text { No. of structures [actually] sprayed }}{\text { No. of structures planned [targeted] }} \times 100$

and

$$
\frac{\text { No. of people [actually]protected }}{\text { No. of people [targeted] }} \times 100
$$

from 2009 to 2017 [2].

\section{Spatial analysis}

A spatial distribution of yearly malaria incidence map was created at sub-zoba level using ArcGIS v.10.2 software.

\section{Statistical analysis}

We used a generalized linear (Poisson regression) model (GLM) to analyze data. This methodology used in many discrete cases predicted studies along with Bayesian STCAR and other GLM techniques. The response variable $Y$ (number of deaths) was distributed as a Poisson random variable, the $\mathrm{E}(\mathrm{Y} / x)$ or $\log [\mathrm{E}(\mathrm{Y} / x)]$ followed a linear model of covariates.

Now, $x=\left(\mathrm{x}_{1}, \mathrm{x}_{2}, \mathrm{x}_{3}, \ldots, \mathrm{x}_{\mathrm{k}}\right)$ set of $\mathrm{k}$ independent predictors defined on a k-dimension real number space i.e. $x \in$ $R^{k}$. The log-link model discussed is written as

$$
E(\text { response })=\lambda T
$$

where $\lambda$ is the rate of occurrence of event (number of deaths etc.) and $\mathrm{T}$ is exposure time.

$$
\log (\lambda)=\alpha+\beta x
$$

$$
\begin{aligned}
& \Lambda=\mathrm{e}^{\alpha+\beta x} \\
& \mathrm{E} \text { (response) }=\mathrm{Te}^{\alpha+\beta x} \\
& \mathrm{E} \text { (response) }=\mathrm{e}^{\log (\mathrm{T})+\alpha+\beta x}
\end{aligned}
$$

When $X_{i}$ increases by 1 unit, $\log (\lambda)$ will increase by $\beta_{\mathrm{i}}$. Thus $\lambda$ is multiplied by $\mathrm{e}^{\beta \mathrm{i}}$ and $\mathrm{e}^{\beta}$ is known as incidence rate. Estimates of $\alpha$ and $\beta$ were obtained by using $\left(Y_{i}, x_{\mathrm{i}}\right)$ available set of observations with the help of maximum likelihood estimator technique.

The probability mass function for the random variable $y$ (count of deaths) following a Poisson distribution is given by

$$
\operatorname{Pr}(\mathrm{Y}=\mathrm{y} \mid x)=\frac{e^{-\lambda} \lambda^{y}}{y !}
$$

where

$$
\lambda=E(Y \mid x)=\mathrm{e}^{\alpha+\beta x}
$$

A dataset of $n$ vectors i.e. $\left(Y_{i}, x_{\mathrm{i}}\right)$ for $\mathrm{i}=1,2,3, \ldots, \mathrm{n}$ provided us estimates of $\alpha$ and $\beta$ which makes the joint probability $\mathrm{P}\left(y_{1}, y_{2}, \ldots, y_{n} / x_{i}\right)$ as large as possible.

It was assumed malaria morbidity and mortality varies by space and time and might be associated with other covariates such as rainfall, temperature, IRS and LLIN coverage. The study variable is a discrete variable (number of cases, deaths). These are aggregated data at subzoba level. In the given circumstances, Poisson regression is more suitable.

$$
\log [\mathrm{E}(\mathrm{Y} / x)]=\log (\text { population })+(\alpha+\beta x)
$$

This equation can be reduced to: $\log [\mathrm{E}(\mathrm{Y} / x) /$ population $]=\alpha+\beta x$

\section{Buishand change point detection test}

Buishand U-test and Buishand range test for quantifying magnitude of change have been used in environmental change analysis from time series datasets [20]. While detecting variable change-point, we set the null hypothesis of zero shift in the data. This method considers the difference of maximum and minimum change in frequency-scaled over standard deviation as a test statistic. It marks the change as significant whenever it finds the test statistic significant which is the ratio of [Max(res)Min(res)]/SD. Changing the set of sample data may produce a different result as even for a very small difference i.e. $[\operatorname{Max}(\mathrm{res})-\operatorname{Min}(\mathrm{res})]$ may turn as significant if SD is very small. We tested the above null hypothesis and marked as change point when test statistic is significant. 
We used interrupted time series (ITS) complimented by the Buishand U-test and Buishand range test for changepoint detection on national level data. We detected corroborated results on all probable change point at times using the trend package in R [21]. However, three variables (the number of people protected by IRS, number of LLINs distributed and TPR) were not significant at 95\% $\mathrm{CI}$ in both tests. The results of the two change detection tests are provided in Additional file 3: Table S2. The ITS used a segmented regression model with formula:

$$
Y_{t}=\beta_{0}+\beta_{1} T+\beta_{2} X_{t}+\beta_{3} T X_{t}
$$

where $\beta_{0}$ is the baseline level at $T=0$ and $\mathrm{Xt}=0, \beta_{1}$ is the change-point of interruption in the outcome linked with a unit time increase after the pre-intervention trend. Meanwhile, $\beta_{2}$ is the (step) level change (new level vertically below $\beta_{1}$ ) subsequent to the intervention and $\beta_{3}$ represents the slope change after the intervention viewed through the interaction of time and intervention $\left(T X_{t}\right)$.

\section{Results}

\section{Changing decline in malaria mortality and incidence}

Considering 2001 as a baseline, malaria mortality declined by over $97 \%\left(R^{2}=0.61\right)$ by the end of 2017 . However, the reported decline was not consistent over the years. Figure 2 shows that while the progress oscillated between malaria gains and losses (reductions and increments), it also remained unstable from year to year with occasional consistencies (Fig. 3). Malaria incidence declined (from 33 to 5 per 1000 population) during the same period by over $86 \%\left(R^{2}=0.3\right)$. Similarly, this decline coupled by an increase in malaria incidence since 2010 dilutes the overall decline recorded.

\section{Test of multicollinearity}

In real data, there is neither perfect multicollinearity nor orthogonality. The determinant of the correlation matrix lies between zero and one (malaria deaths 0.19 and malaria incidences 0.1882 ), and there might be some degree of multicollinearity in the exploratory section of the model. The existence of multicollinearity may be considered as the departure from the orthogonality. The stronger the departure from orthogonality (the value of the standardized determinant to unity), the stronger the degree of multicollinearity and vice versa.

There are several measures which are used to detect multicollinearity in the literature, for example, the determinant method, R-square method, sum of reciprocal eigenvalues, Farrar-Glauber Chi-square method and Red indicator [22, 23]. All these tests the null hypothesis of orthogonality (no correlation) among explanatory variables. We ran the Farrar-Glauber Chi-square test on the data, 648 classes (months of six zones over the period 2009-2017). Results showed that, on average, one class contributes only 1.65 (square of standard normal variate) for a single class.

\section{Model validation}

We computed the mean square error (MSE) which shows the goodness-of-fit in a model. The estimated MSE determines the statistical significance of the factors or predictors under study. The MSE measures the quality of an

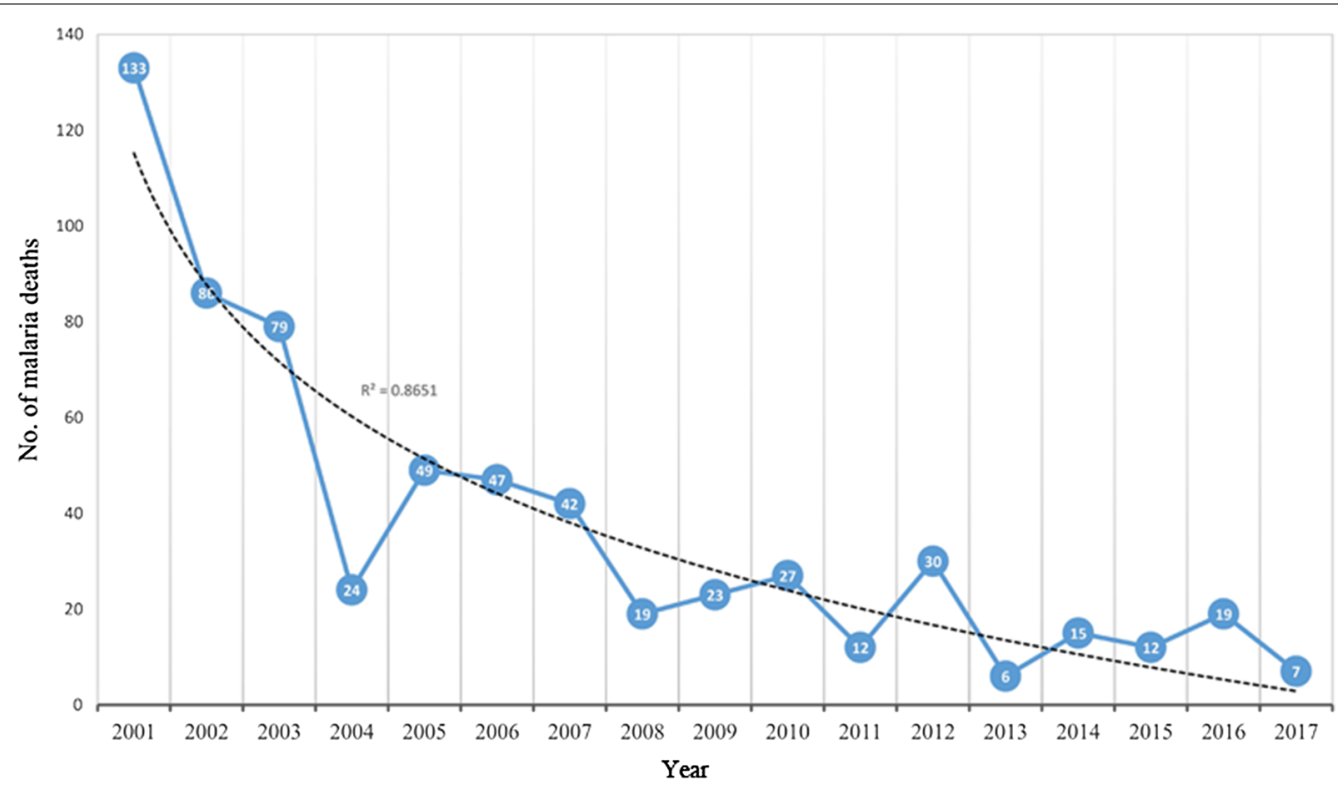

Fig. 2 Number of malaria deaths, 2001-2017 (malaria mortality reductions achieved between 2001 and 2017) 


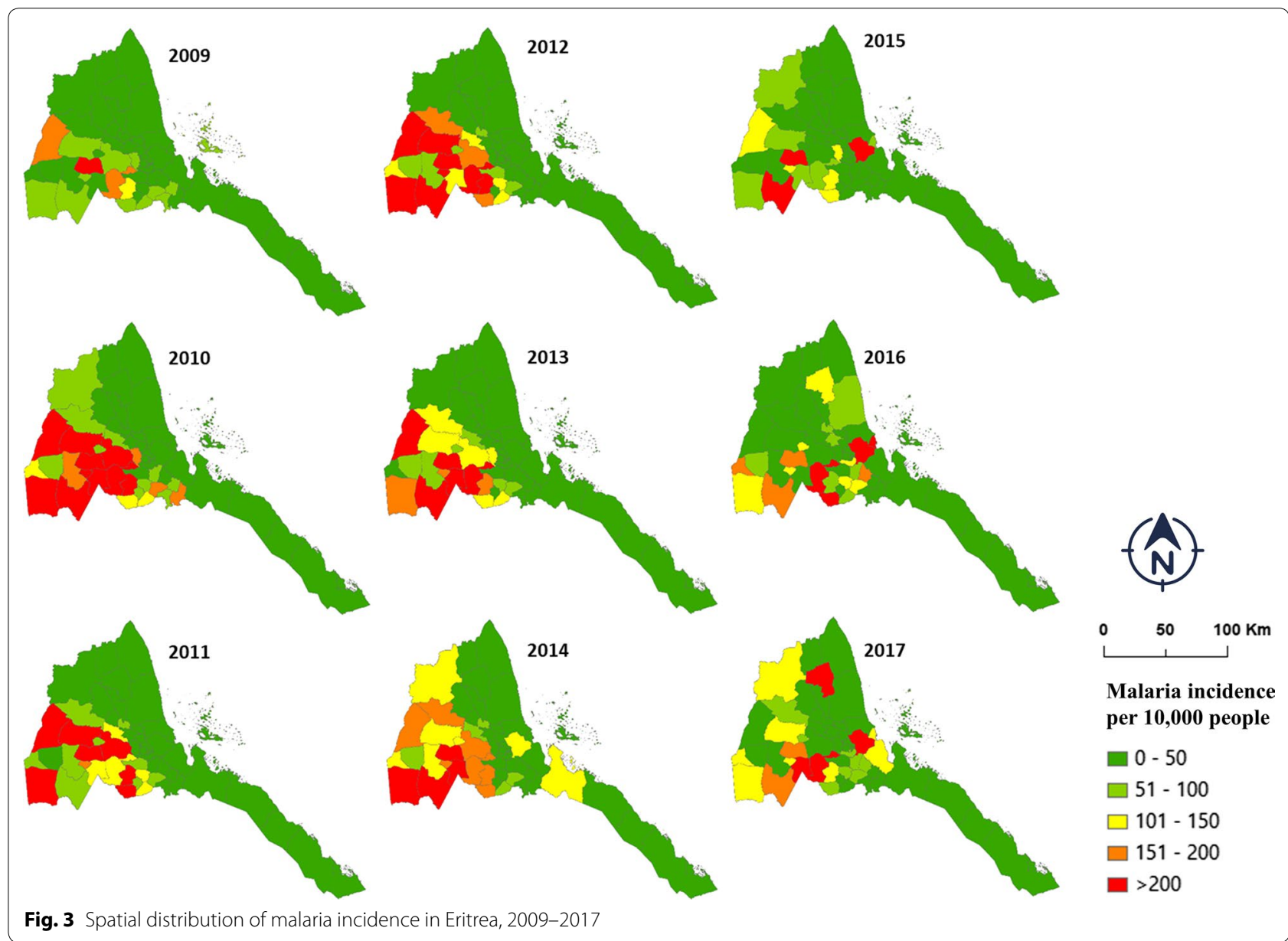

Table 1 Malaria risk factors in Eritrea

\begin{tabular}{|c|c|c|c|c|c|c|}
\hline \multirow[t]{2}{*}{ Model } & \multicolumn{3}{|c|}{ Malaria incidence } & \multicolumn{3}{|c|}{ Mortality } \\
\hline & MSE & Covariate & F-statistic $(d f)$ & MSE & Covariate & F-statistic $(d f)$ \\
\hline \multirow[t]{5}{*}{ All covariates model } & \multirow[t]{5}{*}{1.2256} & LLIN & $6.0664(1,102)^{* * *}$ & \multirow[t]{5}{*}{1.3972} & LLIN & $3.8997(1,102)$ \\
\hline & & Population & $3.7908(1,102)^{* * *}$ & & Population & $1.9997(1,102)$ \\
\hline & & IRS & $27.6361(1,102)^{* * *}$ & & IRS & $0.0597(1,102)$ \\
\hline & & Temperature & $1.2455(1,102)^{* * *}$ & & Temperature & $3.8494(1,102)^{*}$ \\
\hline & & Rainfall & $8.7734(1,102)^{* * *}$ & & Rainfall & $8.8578(1,102)^{* *}$ \\
\hline \multirow[t]{2}{*}{ LLIN and IRS } & \multirow[t]{2}{*}{1.2707} & LLIN & $2.9653(1,105)^{* * *}$ & \multirow[t]{2}{*}{1.3065} & LLIN & $3.0643(1,105)$ \\
\hline & & IRS & $7.5076(1,105)^{* * *}$ & & IRS & $7.2561(1,105)^{* *}$ \\
\hline \multirow[t]{2}{*}{ Temperature and rainfall } & \multirow[t]{2}{*}{1.3754} & Temperature & $4.0844(1,105)^{* * *}$ & \multirow[t]{2}{*}{1.2548} & Temperature & $4.1961(1,105)^{*}$ \\
\hline & & Rainfall & $9.4064(1,105)^{* * *}$ & & Rainfall & $9.7945(1,105)^{* *}$ \\
\hline Only LLIN & 1.1656 & LLIN & $4.8180(1,106)^{* * *}$ & 1.3947 & LLIN & $8.4972(1,106)^{*}$ \\
\hline Only IRS & 1.6138 & IRS & $9.7032(1,106)^{* * *}$ & 1.3237 & IRS & $9.9540(1,106)^{* *}$ \\
\hline Only temperature & 1.2121 & Temperature & $1.4810(1,106)^{* * *}$ & 1.2307 & Temperature & $1.6129(1,106)$ \\
\hline Only rainfall & 1.2917 & Rainfall & $6.2400(1,106)^{* * *}$ & 1.2613 & Rainfall & $6.2488(1,106)^{*}$ \\
\hline
\end{tabular}

${ }^{*} P<0.05,{ }^{* *} P<0.001,{ }^{* * *} P<0.0001$

Note: $P$-value $=$ Probability $\left(F_{(1, \text { error df })} \geq F_{-}\right.$calculated $)$

Abbreviations: MSE, mean square error; LLIN, long-lasting insecticidal nets; IRS, indoor residual spraying; df, degrees of freedom 
estimator being used. The MSE is always positive because of squaring effects of deviation from model estimates. However, this measure does not account for information that could produce a more accurate estimate. Additionally, the MSE varies when there is a high variation in the error magnitude.

For validation purposes, we fitted the model using $80 \%$ of the dataset and validated on the remaining $20 \%$ by computing $\sum\left(\mathrm{Yi}_{\mathrm{i}} \mathrm{Yi}^{\wedge}\right)^{2} / \mathrm{n}$. Table 1 shows all MSEs for various models of mortality and incidence. A good model will be one that has a smaller MSE. The model using LLIN as covariate only is the best predicting model for malaria incidence $(\mathrm{MSE}=1.17$, see Table 1$)$; on the other hand, the model with covariate temperature only is the best predictor for deaths due to malaria.

The measure MSE just provides an estimate for a percentage of validation. It might be different for a different validation percentage. Moreover, it always selects a random sample for the training set and the remaining are used for the validation (test) set. Results of MSE might be different if the same percentage of training and test set is used on various runs. This is because of the selection of random samples (splitting data into train set and test set).

\section{Distribution and use of malaria diagnostic tools}

A downward trend of malaria deaths was reported in Eritrea from 2001 to 2017 (Fig. 3). During the same period, a steady increase of suspected fever cases was diagnosed using microscopy and RDTs (Additional file 4: Figure S1). Meanwhile, the observed significant increase in the number of tested suspected malaria cases using microscopy and RDT denotes an equivalent reduction in cases treated based on clinical diagnosis alone.

\section{Vector control and reported burden of malaria at national and regional level}

Since 2001, IRS, LLIN, and larviciding have been the primary intervention tools for targeting vector control. To strengthen case management, Artemisinin Combination Therapy (ACT) and RDT were also introduced at the community level in 2007 [4]. The introduction and subsequent use of RDTs and ACTs have been increasing while the implementation of IRS and LLINs had not declined, as shown in Additional file 4: Figure S2. Meanwhile, the malaria mortality rate significantly reduced during the same period (Additional file 4: Figure S3).

The distribution of LLINs generally declined between 2001 and $2014\left(R^{2}=0.16\right)$ and increased coverage afterward, while the number of people protected by IRS slightly increased $\left(R^{2}=0.27\right)$. LLIN coverage was associated with the reduction of malaria cases whereas an increase in IRS was associated with increased malaria cases (Table 1). However, only LLIN was significantly (95\% CI: - 1.07-0.06) associated with predicted deaths. A higher temperature was associated with reduced malaria cases whereas increased rainfall was positively associated with increased number of malaria cases. A low temperature in the rainy season was conducive for malaria spread. Changes in both temperature and rainfall were highly significant while predicting the number of malaria cases and deaths. The corrected AIC (AICc) of a log-likelihood model penalized for several covariates.

Based on Fig. $4(\mathrm{a}-\mathrm{h})$, the model using all covariates is the best fit (lowest AICc $=359.33$ ). The vector of predicted number of cases by this model has the highest probability of appearing as a predicted vector from all
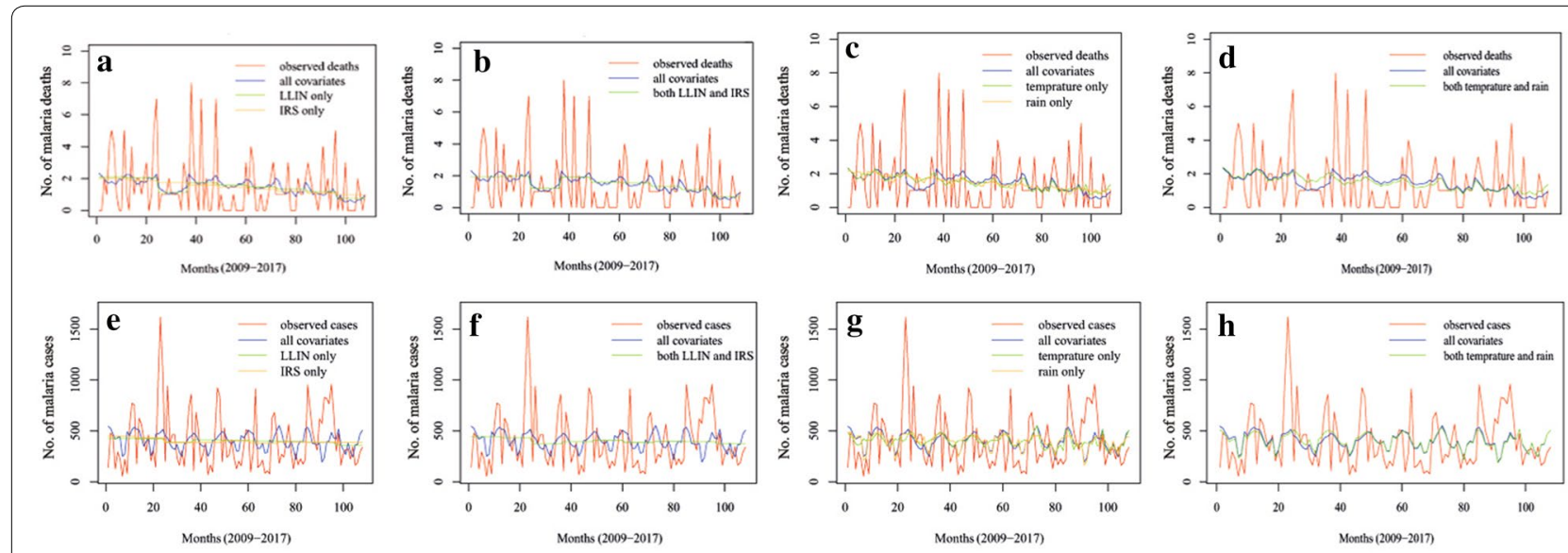

Fig. 4 a LLIN and IRS as individual predictors of malaria deaths. b LLIN and IRS as compound predictors of malaria deaths. c Temperature and rainfall as compound predictors of malaria deaths. $\mathbf{d}$ Temperature and rainfall as individual predictors of malaria deaths. e LLIN and IRS as individual predictors of malaria cases. $\mathbf{f}$ LLIN and IRS as compound predictors of malaria cases. $\mathbf{g}$ Temperature and rainfall as compound predictors of malaria cases. $\mathbf{h}$ Temperature and rainfall as individual predictors of malaria cases 
given models. LLIN and IRS (Fig. 4e) is the second likely close line to the actual cases line. This suggests that it is the correlation of a covariate or set of covariates, which makes a covariate efficient predictor.

The introduction of ACTs in 2007 may explain the spatiotemporal distribution (Additional file 4: Figure S4) and change detected in the subsequent years (Additional file 4: Figure S5). Additional file 4: Figure S6 shows the evaluation of the effectiveness of the population-wide health intervention.

The observed change(s) detects whether cases increased or decreased (probability of an event occurring e.g. death) is significantly high (low i.e. different) at that point in time (Additional file 3: Table S2). The Buishand U-test and time series homogeneity tests allow a change point to be detected (Additional file 3: Table S2). The Buishand U-test is more sensitive than the Buishand range test and detects whether cases increased or decreased in a certain time period.

\section{Discussion}

Through its control efforts, Eritrea has made tremendous progress in the fight against malaria in the past decade. The 2009-2017 effective malaria control programme adopted an intervention approach that strengthened vector control, and effective case management [13, 24]. These strategies, coupled with a good reception from the community, resulted in a significant drop in malaria cases [13].

The foregoing observation is not surprising given the 2011 survey finding of no effect on malaria incidence even after the introduction of IRS in Gash-Barka despite the area having high net coverage and low malaria incidence $[16,19]$.

The change point for the mortality rate in 2007 could be associated with the introduction of RDTs at the national scale that might be related to diagnosis and treatment at the community level. Although this huge drop was attained earlier, the country did not move to eliminate malaria due to various reasons, ranging from failure to sustain such progress, operational challenges in implementing interventions and the lack of a deliberate plan to move from control towards elimination.

In the latter years, the increased IRS and LLINs coverage compared to the past did not result in a continued reduction in cases or even deaths. This is because vector control was applied to the more seasonal or endemic regions where malaria transmission remains in pockets of persistent areas. Thus, although there is no significant reduction in IRS or LLIN, efficiency has improved by targeting high-risk populations and ensuring high intervention coverage to yield the result.

As morbidity and mortality further reduced, cycles of surge periods became shorter (Figs. 2, 3). This is a sign of making progress toward zero cases, and such frequent surges might be due to a loss of immunity as the naive population increases. These gains require more strategic approaches strengthening surveillance, monitoring, and a functioning rapid reporting system.

The benefits from optimal RDTs at limited capacity [24], and the rational use of anti-malarial drugs [25] marked the move away from clinical treatment [26]. Missing the infected individuals driving residual transmission (individuals with clinical immunity) or potential sequestration $[27,28]$ of $P$. vivax, potentially explains the unstable malaria incidence and resultant epidemics or outbreaks in the latter years. A small fraction of clinical diagnosis implies that it could increase drug resistance due to misdiagnosis and overtreatment [25, 29]. It will also be challenging and take longer to reach a stable suppression of malaria transmission and transmission tail. A transmission tail implies that it requires more investment and resilience because any drop-off would cause disease resurgence due to the population's waning immunity from lack of exposure. This is not surprising because malaria becomes more elusive as transmission reduces to very low levels usually deemed suitable for elimination, while the efficiency of currently available tools becomes compromised.

Eritrea can drastically reduce the number of malaria cases or even move towards elimination. The country's move to conducting regular therapeutic efficacy studies [26], insecticide resistance monitoring [30], case management, improved diagnosis [31], mobilization of trained staff [32] and financial resources [11], regularly updating risk maps [33-38], monitoring and evaluation [18, 30, 39-43], can help to sustain the gains and achieve elimination.

Resource allocation tools and methods must be strategically applied in order to balance control in endemic zones such as Gash-Barka and prevent reintroduction in areas with low to zero cases. Likewise, behavioral change communication remains essential for the population to stay alert and ensure continuity in the utilization of preventive interventions such as LLINs until an informed decision is made by the government to withdraw or halt malaria prevention services from a certain area. Given environmental management, LLINs and IRS, 
complimented with larviciding in certain areas, remain the only vector control interventions being implemented in the country. With current plans focusing on elimination through testing, treating, documentation, reporting and tracking of every fever/malaria case (WHO's Test, Treat and Track approach), Eritrea must introduce mobile phone technology for real-time reporting of malaria cases from all health facilities [44].

We used routinely collected malaria cases data for this study. Many cases were not confirmed by RDT and microscopy but were based on clinical signs and symptoms. Both RDT and microscopy have limited sensitivity and specificity and are particularly likely to misclassify individuals with low levels of parasitemia. HRP2-detecting RDTs report false negative results on $P$. falciparum species due to deletion of the Pfhrp2 gene as shown by Pati et al. [45] in 2015. Finally, the census populations used were derived from estimates because there has not been any census in Eritrea since 1994. Despite all these challenges, this study documented the progress and identified challenges to control and eliminate malaria in Eritrea with longer time series data. Any variation generated by the general discussion of malaria without speciation (P. vivax vs P. falciparum) is covered by evidence [46] that diagnostic tests (microscopy and RDTs) were able capture both invariably.

\section{Conclusions}

The progress achieved by Eritrea towards malaria elimination should be further maintained and improved. Efforts should be sustained to keep effective malaria control and eventual elimination of the disease in the country. Distribution, coverage and utilization of malaria control and elimination tools should be optimized and sustained to safeguard these gains. Consistent annual performance evaluation of malaria indicators would ensure a continuous learning process from gains/ threats of epidemics and resurgence in regions already earmarked for elimination. As elimination of malaria becomes more imminent, a stronger malaria surveillance system will also need to be well equipped to tackle potential malaria case importation. Hence, prior operationalization of existing interventions and efforts will go a long way towards elimination. It will require sustained support and commitment from the National Malaria Control Programme, as well as political leaders coupled with adequate local resource mobilization.

\section{Supplementary information}

Supplementary information accompanies this paper at https://doi. org/10.1186/s13071-020-3974-x.

Additional file 1: Table S1. Milestones of malaria control programme in Eritrea.

Additional file 2: Text S1. Additional methods and climatic parameters by geographical region.

Additional file 3: Table S2. Change detection tests to confirm time points with identifiable significant changes.

Additional file 4: Figure S1. Trends in malaria cases and method of diagnosis in Eritrea, 2001 to 2017 (* No data available for the number tested by both RDT and microscopy in 2016 and 2017). Figure S2. Trends in type and quantity of interventions in relation to mortality, 2001 to 2017. Figure S3. Malaria incidence, admissions and mortality rates, 2001 to 2017. Figure S4. Spatial distribution of malaria prevalence in Eritrea, 2009 to 2017. Figure S5. Eritrea malaria incidence, 2001-2017 after introducing ACTs in 2003 (as change point). Interrupted time series with a level change regression model, and a (line) predicted trend using the unadjusted regression model. Figure S6. Malaria incidence in Eritrea, 2001-2017, step vs step change-only models. No significant difference was detected using the F-test, which accounts for the over-dispersion.

\section{Abbreviations}

ACT: artemisinin combination therapy; ALMA: African Leaders Malaria Alliance Award; CFSR: climate forecast system reanalysis; CHAs: community health assistants; CHIRPS: Climate Hazards Group Infrared Rainfall with Stations; HMIS: Health Management Information System; HQ: headquarters; IRS: indoor residual spraying; LLIN: long-lasting insecticidal nets; MDGs: Millennium Development Goals; NCEP: National Centers for Environmental Prediction; NMCP: National Malaria Control Programme; RDT: rapid diagnosis test; TPR: test positivity rate; USGS: United States Geological Survey; WHO: World Health Organization.

\section{Acknowledgments}

Not applicable.

\section{Authors' contributions}

SM and AG collected data and contributed to study design and writing the manuscript. BZ, AJRM and AKM contributed to writing the manuscript. JL, MYS and UH conceived the study design, and contributed to data preparation, analysis and drafting the manuscript. All authors read and approved the final manuscript.

\section{Funding}

UH was funded in part by the Emerging Pathogens Institute at the University of Florida and the College of Liberal Arts and Sciences, as part of the University of Florida Pre-eminence Initiative.

\section{Availability of data and materials}

Data supporting the conclusions of this manuscript are provided within the article and its additional files and original datasets are available from the corresponding author upon request.

\section{Ethics approval and consent to participate}

Not applicable. The Ministry of Health, Eritrea determined that no ethical approval was required since we analyzed de-identified, delinked aggregated data.

Consent for publication Not applicable. 


\section{Competing interests}

The authors declare that they have no competing interests.

\section{Author details}

${ }^{1}$ National Malaria Control Programme, Ministry of Health, Asmara, Eritrea.

${ }^{2}$ School of Geography and Environmental Sciences, Ulster University, Coleraine, UK. ${ }^{3}$ Department of Biostatistics, University of North Carolina at Chapel Hill, Chapel Hill, NC, USA. ${ }^{4}$ Public Health and Infection Research Group, Faculty of Health Sciences, Universidad Tecnológica de Pereira, Pereira, Risaralda, Colombia. ${ }^{5}$ Medical School, Faculty of Health Sciences, UniFranz, Cochabamba, Bolivia. ${ }^{6}$ Grupo de Investigación Biomedicina, Faculty of Medicine, Fundación Universitaria Autónoma de las Américas, Pereira, Risaralda, Colombia. ${ }^{7}$ Department of Sociology and Anthropology, St Louis University, St. Louis, MO, USA. ${ }^{8}$ Department of Statistics, Quaid-i-Azam University, Islamabad, Pakistan. ${ }^{9}$ Department of Geography, University of Florida, Gainesville, $\mathrm{FL}$, USA. ${ }^{10}$ Emerging Pathogens Institute, University of Florida, Gainesville, FL, USA. ${ }^{11}$ Department of Biostatistics and Epidemiology, University of North Texas Health Science Center, Fort Worth, TX, USA.

Received: 23 January 2019 Accepted: 17 February 2020 Published online: 12 March 2020

\section{References}

1. Yebio NW. The secrets behind Eritrea's health sector success; 2016. http:// www.shabait.com/articles/nation-building/22138-the-secrets-behin d-eritreas-health-sector-success-?format=pdf. Accessed 24 Oct 2019.

2. WHO. World malaria report 2017. Geneva: World Health Organization; 2018.

3. Phumaphi J. African heads of state celebrate historic progress in malaria fight; 2016. http://alma2030.org/sites/default/files/alma_rewards_ pdf/2016_alma_awards_for_excellence_overview-english.pdf. Accessed 24 Oct 2019.

4. Memoire A. National Malaria Programme-Performance Review aidememoire; 2013. https://endmalaria.org/sites/default/files/Eritrea-Themalaria-program-performance-review-20131.pdf. Accessed 24 Oct 2019

5. WHO. Global technical strategy for malaria 2016-2030. Geneva: World Health Organization; 2015. http://apps.who.int/iris/bitstream/10665 /176712/1/9789241564991_eng.pdf?ua=1. Accessed 24 Oct 2019.

6. Africa Union. Catalytic framework to end AIDS, TB and eliminate malaria in Africa By 2030; 2016. https://au.int/sites/default/files/newsevents/ workingdocuments/27513-wd-sa16949_e_catalytic_framework.pdf. Accessed 24 Oct 2019

7. Berhane A, Russom M, Bahta I, Hagos F, Ghirmai M, Uqubay S. Rapid diagnostic tests failing to detect Plasmodium falciparum infections in Eritrea: an investigation of reported false negative RDT results. Malar J. 2017;16:105.

8. Shililu J, Ghebremeskel T, Seulu F, Mengistu S, Fekadu H, Zerom M, et al. Larval habitat diversity and ecology of anopheline larvae in Eritrea. J Med Entomol. 2003:40:921-9.

9. Chanda E, Ameneshewa B, Mihreteab S, Berhane A, Zehaie A, Ghebrat Y, et al. Consolidating strategic planning and operational frameworks for integrated vector management in Eritrea. Malar J. 2015;14:488.

10. United Nations Statistics Division. Eritrea: country profile; 2017. http:// data.un.org/CountryProfile.aspx?crName=Eritrea. Accessed 24 Oct 2019.

11. Ministry of Health, Eritrea. The State of Eritrea Ministry of Health NonCommunicable Diseases Policy; 2008. https://www.iccp-portal.org/syste m/files/plans/ERI_B3_NCD\%20POLICY\%20FOR\%20ERITREA.pdf. Accessed 24 Oct 2019.

12. Ceccato P, Ghebremeskel T, Jaiteh M, Graves PM, Levy M, Ghebreselassie S, et al. Malaria stratification, climate, and epidemic early warning in Eritrea. Am J Trop Med Hyg. 2007;77(Suppl.):61-8.

13. Nyarango PM, Gebremeskel T, Mebrahtu G, Mufunda J, Abdulmumini U, Ogbamariam A, et al. A steep decline of malaria morbidity and mortality trends in Eritrea between 2000 and 2004: the effect of combination of control methods. Malar J. 2006;5:33.

14. Saha S, Moorthi S, Pan HL, Wu X, Wang J, Nadiga S, et al. NCEP climate forecast system reanalysis (CFSR) selected hourly time-series products, January 1979 to December 2010. Research data archive at the National
Center for Atmospheric Research, Computational and Information Systems Laboratory. 2010. http://rda.ucar.edu/datasets/ds093.0/. Accessed 24 Mar 2016.

15. Funk C, Peterson P, Landsfeld M, Pedreros D, Verdin J, Shukla S, et al. The climate hazards infrared precipitation with stations-a new environmental record for monitoring extremes. Sci Data. 2015;2:150066.

16. Kilian A, Koenker H, Paintain L. Estimating population access to insecticide-treated nets from administrative data: correction factor is needed. Malar J. 2013;12:259.

17. Haque U, Overgaard HJ, Clements ACA, Norris DE, Islam N, Karim J, et al. Malaria burden and control in Bangladesh and prospects for elimination: an epidemiological and economic assessment. Lancet Global Health. 2014;2:E98-105.

18. Kamuliwo M, Chanda E, Haque U, Mwanza-Ingwe M, Sikaala C, KatebeSakala C, et al. The changing burden of malaria and association with vector control interventions in Zambia using district-level surveillance data, 2006-2011. Malar J. 2013;12:437.

19. WHO. World Malaria Report, 2010. Geneva: World Health Organization; 2011. http://www.who.int/malaria/world_malaria_report_2010/en/index .html. Accessed 24 Oct 2019.

20. Jaiswal RK, Lohani AK, Tiwari HL. Statistical analysis for change detection and trend assessment in climatological parameters. Environ Process. 2015;2:729-49.

21. Pohlert T. Non-parametric trend tests and change-point detection; 2018. https://cran.r-project.org/web/packages/trend/vignettes/trend.pdf. Accessed 22 Jan 2019.

22. Farrar DE, Glauber RR. Multicollinearity in regression analysis: the problem revisited. Rev Econ Statist. 1967;49:92-107.

23. Kovács $P$, Petres $T$, Tóth $L$. A new measure of multicollinearity in linear regression models. Int Stat Rev. 2005;73:405-12.

24. Aidoo M. Perspective piece. Am J Trop Med Hyg. 2013;89:403-6.

25. Gherezghiher VT. Bridging the gap between communities and health services in Eritrea; 2009. http://www.medicusmundi.ch/de/bulletin/ mms-bulletin/30-jahre-nach-alma-ata-die-zukunft-von-community-healt h/im-zeichen-von-alma-ata-community-health-and-empowerment/ bridging-the-gap-between-communities-and-health-services-in-eritrea. Accessed 24 Oct 2019.

26. Haque U, Glass GE, Haque W, Islam N, Roy S, Karim J, et al. Antimalarial drug resistance in Bangladesh, 1996-2012. Trans R Soc Trop Med Hyg. 2013:107:745-52

27. White NJ. Malaria parasite clearance. Malar J. 2017;16:88.

28. Pampana E. A textbook of malaria eradication. Oxford: Oxford University Press; 1969.

29. Schlagenhauf $\mathrm{P}$, Grobusch MP, Hamer DH, Asgeirsson H, Jensenius M Eperon $\mathrm{G}$, et al. Area of exposure and treatment challenges of malaria in Eritrean migrants: a GeoSentinel analysis. Malar J. 2018;17:443.

30. Chanda E, Chanda J, Kandyata A, Phiri FN, Muzia L, Haque U, et al. Efficacy of ACTELLIC 300 CS, pirimiphos methyl, for indoor residual spraying in areas of high vector resistance to pyrethroids and carbamates in Zambia. J Med Entomol. 2013;50:1275-81.

31. Mukonka VM, Chanda E, Kamuliwo M, Elbadry MA, Wamulume PK, Mwanza-Ingwe M, et al. Diagnostic approaches to malaria in Zambia, 2009-2014. Geospat Health 2015:10:330.

32. Hemingway J, Shretta R, Wells TNC, Bell D, Djimdé AA, Achee N, et al. Tools and strategies for malaria control and elimination: What do we need to achieve a grand convergence in malaria? PLoS Biol. 2016;14:e1002380.

33. Chanda E, Mukonka VM, Kamuliwo M, Macdonald MB, Haque U. Operational scale entomological intervention for malaria control: strategies, achievements and challenges in Zambia. Malar J. 2013;12:10.

34. Haque U, Soares Magalhaes RJ, Mitra D, Kolivras KN, Schmidt WP, Haque R, et al. The role of age, ethnicity and environmental factors in modulating malaria risk in Rajasthali, Bangladesh. Malar J. 2011;10:367.

35. Haque U, Hashizume M, Sunahara T, Hossain S, Ahmed SM, Haque R, et al. Progress and challenges to control malaria in a remote area of Chittagong hill tracts, Bangladesh. Malar J. 2010;9:156.

36. Haque U, Glass GE, Bomblies A, Hashizume M, Mitra D, Noman N, et al. Risk factors associated with clinical malaria episodes in Bangladesh: a longitudinal study. Am J Trop Med Hyg. 2013:88:727-32.

37. Haque U, Huda M, Hossain A, Ahmed SM, Moniruzzaman M, Haque R. Spatial malaria epidemiology in Bangladeshi highlands. Malar J. 2009:8:185. 
38. Reid H, Haque U, Clements ACA, Tatem AJ, Vallely A, Ahmed SM, et al. Mapping malaria risk in Bangladesh using Bayesian geostatistical models. Am J Trop Med Hyg. 2010;83:861-7.

39. Ohrt C, Roberts KW, Sturrock HJ, Wegbreit J, Lee BY, Gosling RD. Information systems to support surveillance for malaria elimination. Am J Trop Med Hyg. 2015;93:145-52.

40. Cao J, Sturrock HJW, Cotter C, Zhou SS, Zhou HY, Liu YB, et al. Communicating and monitoring surveillance and response activities for malaria elimination: China's"1-3-7" strategy. PLoS Med. 2014;11:e1001642.

41. The Global Health Group UGHS. Background paper, suveillance systems to facilitate malaria elimination. Health Educ Res. 2014;29:33.

42. Mukonka VM, Chanda E, Haque U, Kamuliwo M, Mushinge G, Chileshe J, et al. High burden of malaria following scale-up of control interventions in Nchelenge District, Luapula Province, Zambia. Malar J. 2014;13:153.

43. Simon C, Moakofhi K, Mosweunyane T, Jibril HB, Nkomo B, Motlaleng M, et al. Malaria control in Botswana, 2008-2012: the path towards elimination. Malar J. 2013;12:458.
44. Francis F, Ishengoma DS, Mmbando BP, Rutta ASM, Malecela MN, Mayala $B$, et al. Deployment and use of mobile phone technology for real-time reporting of fever cases and malaria treatment failure in areas of declining malaria transmission in Muheza district north-eastern Tanzania. Malar J. 2017;16:308.

45. Pati P, Dhangadamajhi G, Bal M, Ranjit M. High proportions of pfhrp2 gene deletion and performance of HRP2-based rapid diagnostic test in Plasmodium falciparum field isolates of Odisha. Malar J. 2018;17:394.

46. Berhane A, Anderson K, Mihreteab S, Gresty K, Rogier E, Mohamed S, et al. Major threat to malaria control programs by Plasmodium falciparum lacking histidine-rich protein 2, Eritrea. Emerg Infect Dis. 2018;24:462-70.

\section{Publisher's Note}

Springer Nature remains neutral with regard to jurisdictional claims in published maps and institutional affiliations.
Ready to submit your research? Choose BMC and benefit from:

- fast, convenient online submission

- thorough peer review by experienced researchers in your field

- rapid publication on acceptance

- support for research data, including large and complex data types

- gold Open Access which fosters wider collaboration and increased citations

- maximum visibility for your research: over $100 \mathrm{M}$ website views per year

At BMC, research is always in progress.

Learn more biomedcentral.com/submissions 